\title{
Neutrophil functions and clinical performance after total fasting in patients with rheumatoid arthritis
}

\author{
ANN-MARI UDÉN, ${ }^{1}$ LUDVIG TRANG,$^{2}$ NIKOS VENIZELOS, ${ }^{3}$ AND \\ J A N PALMBLA D \\ From the ${ }^{1}$ Fourth Department of Medicine and the ${ }^{3}$ Department of Clinical Bacteriology, the Karolinska \\ Institute at Södersjukhuset and the ${ }^{2}$ Department of Medicine, St Erik's Hospital, Stockholm, Sweden
}

SUMMARY The effects of fasting for 7 days were investigated in 13 patients with rheumatoid arthritis (RA) in comparison with a control regimen in a cross-over trial. The effects of fasting on clinical performance and blood neutrophil functions were studied. During fasting, with a mean weight loss of $5 \cdot 1 \mathrm{~kg}$, clinical inflammation in the joints and the erythrocyte sedimentation rate (ESR) decreased. During the control period the joints either remained unchanged or deteriorated, and no change was observed in the body weight or the ESR. The locomotion of neutrophils under agarose, induced by a reference serum, decreased during the fasting period $(\mathrm{p}<0 \cdot 001)$, but no change in their locomotion was induced by an Escherichia coli bacterial factor. During the control period, however, the locomotion induced by either stimulant was significantly decreased. Generation of migration-stimulating factors from the patients' plasma declined 3 days after the end of fasting $(p<0 \cdot 001)$. The adherence of the neutrophils to nylon fibres was unchanged during both periods. The bactericidal capacity improved during fasting, both in comparison with the initial value $(p<0.005)$ and with the values from the control period $(p<0.01)$. An association was found between improvement in inflammatory activity of the joints and enhancement of neutrophil bactericidal capacity. Fasting appears to improve the clinical status of patients with RA. This could partly be due to the observed changes in the functions of the neutrophils, since the latter contribute to the inflammatory joint reactions.

Fasting has for a long time been thought to be of value in the treatment of various diseases. An increased interest in its effects has been noted in recent years, and claims have been made that fasting ameliorates joint symptoms in rheumatoid arthritis. However, we do not know of scientifically controlled studies on this subject.

Fasting could influence the activity of rheumatoid arthritis by several mechanisms. Previous studies have shown that fasting by healthy subjects was accompanied by a decreased neutrophil bacterial killing and depressed lymphocyte response to mitogens, decreased serum levels of several acute-phase reactants and complement factors, and increased serum cortisol concentrations. ${ }^{1-4}$ Any or all of these might contribute to the proposed beneficial influence of fasting on rheumatoid arthritis. However, other

Accepted for publication 15 December 1981.

Correspondence to Dr A. M. Udén, Karolinska Institutet, Medicinska kliniken IV, Södersjukhuset, S-100 64 Stockholm, Sweden. mechanisms might also contribute-for example, dehydration and effects of ketosis on the function of the central nervous system to name but 2 .

The aim of the present study was to see in a crossover trial whether clinical improvement occurred in 13 patients with rheumatoid arthritis (RA) who fasted for 7 days. Moreover, since the polymorphonuclear (PMN) neutrophil granulocyte is one of the principal effector cells in the rheumatoid inflammatory reaction, its functions were investigated by in-vitro assays. These included; adherence (being a prerequiste for emigration of cells from the blood vessels into the tissues, as well as being critical for migration); migration stimulated by 2 unrelated cytotaxins (one being serum); the ability to kill Staphylococcus aureus; and the production of PMN-migration-stimulating substances in plasma samples from the patients.

Finally we assessed whether possible changes in the clinical inflammatory activity during fasting were related to changes of PMN functions and also to serum cortisol concentrations. 


\section{Material and methods}

The group consisted of 13 patients with classical or definite rheumatoid arthritis (RA) according to the criteria of American Rheumatism Association. ${ }^{5}$ All the patients were female, with a mean age of 42 years (range 24-60 years), and all appeared to be healthy except for their RA. These 13 patients were randomly selected from the RA patients who volunteered for the study.

Criteria for exclusion were treatment with gold salts, penicillamine levamisole, antimalarials, or cytostatic drugs within the last 3 months before the trial. Steriods were discontinued at least 2 weeks before the study. Other criteria of exclusion were concomitant diseases and obvious extremes of underor overweight.

The investigation was designed to compare the effect of treatment, which consisted either of 7 days of fasting or of 7 days of normal food intake in the same patients in a cross-over manner (Fig. 1). Thus each patient was admitted to hospital (Department of Rheumatology, St Erik's Hospital, Stockholm) for 2 fortnight periods, one being the control and one the fasting period. The fasting period started with 3 days of habituation to hospital conditions. During the next 7 days the patients had no food and were allowed to drink only non-calorie beverages. Then followed 3 days of gradual return to normal food intake. All drugs except paracetamol were stopped on admission to the hospital. Tobacco and coffee were prohibited during the trial. The patients had the usual physical therapy, occupational therapy, and all-day hospital activities. Blood samples were taken on the first, the fourth, and the last (i.e., 8th) fasting day and on the third day after feeding was started again (day 11). Venepunctures were always performed at the same time in the morning. The control period was identical in every other respect to the fasting period except for food intake ad libitum. The interval between the fasting and control period was 3 to 6 weeks.

Nine patients started the investigation with the control period and 4 with the fasting period. The decision which period would initiate the trials was randomly determined and not known to the patients until the start of the experimental period. Clinical evaluation of the joints was made every other day at the same time of day (in the morning) and always by the same investigator.

\section{JOINT VARIABLES}

The evaluation of joint status included joint count, Ritchie's index and Lansbury's index, and duration of morning stiffness. For the joint count the peripheral joints were tested for tenderness on palpation or pain on passive motion; the number of involved joints was recorded. For Ritchie's index the same joints were tested and graded on a 4-point scale for tenderness. ${ }^{6}$ For Lansbury's index the same joints were recorded and tested, and the size of the involved joints was taken into account. ${ }^{7}$ Duration of morning stiffness was recorded on a 5-point scale with the endpoints $1=$ no morning stiffness to $5=>3$ hours of stiffness.

\section{LAB ORATORY METHODS}

The erythrocyte sedimentation rate (ESR) wa determined according to Westergren's method.

Serum cortisol concentrations were measured with a fluorimetric technique.

Leucocyte suspensions were prepared according to Afzelius et al. ${ }^{8}$

The stimulated and spontaneous locomotion of PMNs was assayed by a modification of a method measuring PMN migration under agarose after incubation for 3 hours. ${ }^{8}$ Either a sterile $E$. coli bacterial filtrate $(\mathrm{BF})$ or pooled human $\mathrm{AB}$ serum was used as a chemotactic factor. The mean value of the dayto-day variation (standard deviation as percentage of
THE COURSE OF THE FASTING EXPERIMENT

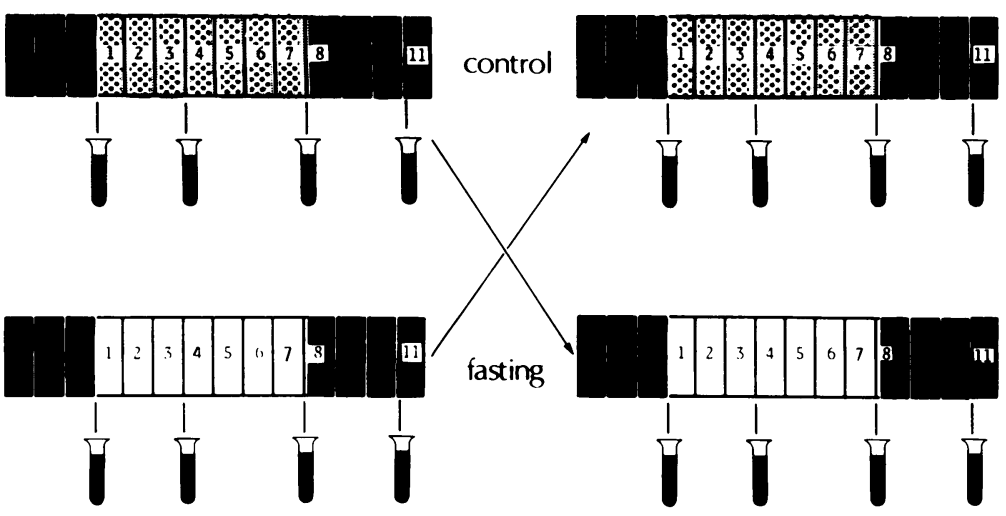

Fig.1 The course of the experiment. Venous blood samples, indicated by the test-tubes, were obtained at about 8.00 a.m. Black fields indicate pre- and postfasting days in the fasting period and pre- and postcontrol days in the control period, when food intake was ad libitum. 


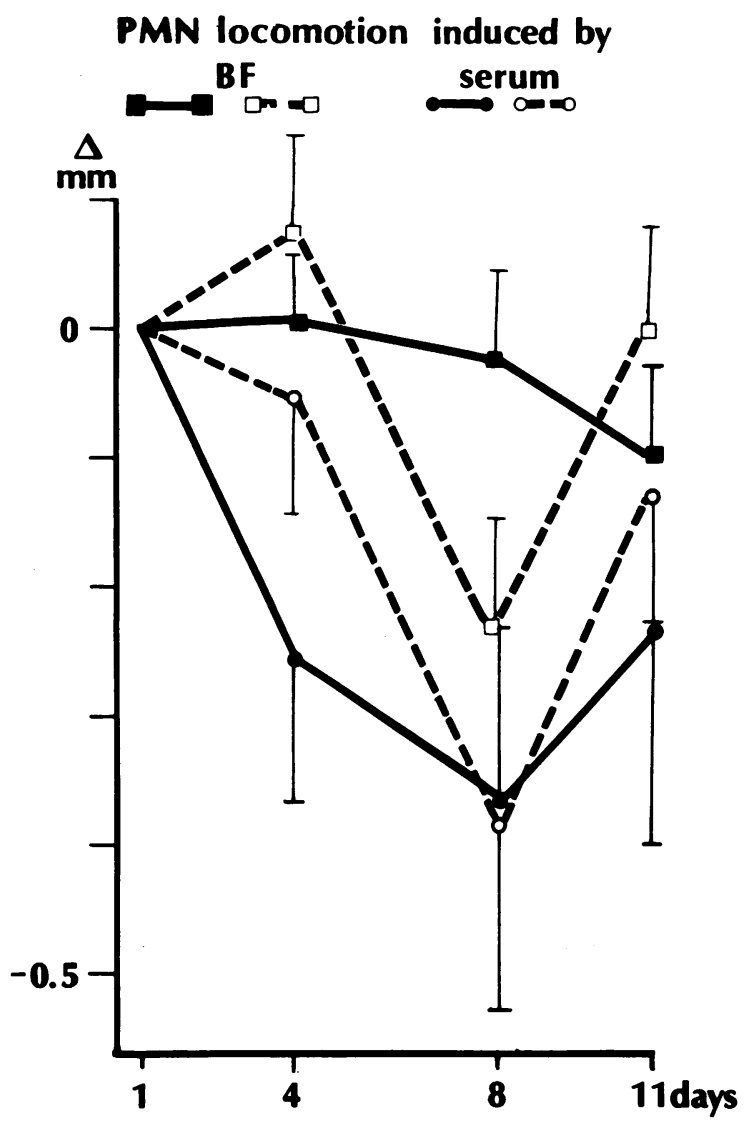

Fig. 2 Deviations from day 1 in PMN locomotion under agarose, stimulated by $B F$ or serum. Mean and $S E$ values. Filled symbols (- and $\bullet-\bullet$ ) represent the fasting period and open symbols ( $\square--\square$ and $\left.0_{-}-\infty\right)$ the control period. The mean values $( \pm S D)$ for the $R A$ patients on day 1 and 11 of the control period were $0.92 \pm 0.18$ and $0.92 \pm 0.21 \mathrm{~mm}$, respectively, when $B F$ was the cytotaxin, and $1 \cdot 32 \pm 0 \cdot 18$ and $1 \cdot 18 \pm 0 \cdot 30 \mathrm{~mm}$, respectively, when serum was the cytotaxin. The normal values (mean \pm 2 $S D)$ for healthy controls are 0.65-1.34 mm for $B F$-stimulated migration and 0.88-1.63 $\mathrm{mm}$ for serum-stimulated migration. the mean) of granulocyte migration induced by BF for 3 subjects assayed as above was $6.5 \%$. The reference values are given in Fig. 2 and Table 1.

The generation of cytotaxins in plasma samples from the patients was assessed as described above. The plasma samples were obtained on the same occasions as when granulocytes were collected, and they were frozen at $-50^{\circ} \mathrm{C}$ until all 8 samples from each patient could be analysed simultaneously undiluted and diluted 50\% with Parker 199 medium. From preliminary studies it was found that further dilutions gave only a very weak migration response after contact with agarose. Granulocytes from healthy blood bank donors, blood group $\mathrm{O}$, were used, and instead of the pooled serum as chemotactic factor the heparinised plasma samples from the patients were added to the other wells.

PMN adherence was assayed by the nylon fibre column method described by MacGregor et al. ${ }^{9}$ The results are given as percentage of PMNs adhering to the fibres. The reference value based on analyses of 104 healthy subjects is given in Table 1 . The day-today variation (standard deviation as percentage of the mean) for a single patient is approximately $5 \%$.

PMN bactericidal capacity was analysed as described previously. ${ }^{1810}$ The results are given as the percentages of living bacteria after 45 and 90 minutes of incubation of the initial counts. The reference values are given in Fig. 3. The day-to-day variation for a single subject and other measures of reproducibility have been presented previously. ${ }^{10}$

Statistical analyses. Changes during the fasting and control periods were checked by a comparison of the individual test values of days $1,4,8$, and 11 by means of a 2-way analysis of variance followed by Student's $t$ test. Differences between the fasting and control periods were performed by comparing paired values for the deviations $(\Delta)$ from day 1 with those on the appropriate days of the respective period by the same methods (since the day 1 values of both periods were not identical). Likewise Student's $t$ test for independent data was used for assessing possible differences between RA and control subjects.

Table 1 PMN spontaneous migration, generation of cytotaxins from the plasma samples, and adherence in patients with rheumatoid arthritis during the fasting $(F)$ and control $(C)$ periods. Mean and $S D$ values

\begin{tabular}{|c|c|c|c|c|c|c|}
\hline & & Day 1 & Day 4 & Day 8 & Day 11 & $\begin{array}{l}\text { Normal values } \\
\text { (mean } \pm 2 S D)\end{array}$ \\
\hline \multirow[t]{2}{*}{ Spontaneous migration, $\mathrm{mm}$} & C & $0.16 \pm 0.03+$ & $0.19 \pm 0.05^{*}$ & $0 \cdot 17 \pm 0 \cdot 05$ & $0 \cdot 16 \pm 0 \cdot 05^{\dagger}$ & \multirow{2}{*}{$0 \cdot 09-0 \cdot 28$} \\
\hline & $\mathbf{F}$ & $0 \cdot 15 \pm 0.04$ & $0 \cdot 11 \pm 0.03^{*}$ & $0 \cdot 14 \pm 0 \cdot 02$ & $0 \cdot 13 \pm 0 \cdot 03$ & \\
\hline $\begin{array}{l}\text { Migration towards patients own } \\
\text { plasma diluted } 50 \%, \mathrm{~mm}\end{array}$ & $\begin{array}{l}\text { C } \\
\text { F }\end{array}$ & $\begin{array}{l}0.78 \pm 0.30 \\
0.94 \pm 0.31\end{array}$ & $\begin{array}{l}0.72 \pm 0.26 \\
0.94 \pm 0.30\end{array}$ & $\begin{array}{l}0: 72 \pm 0 \cdot 31 \\
0 \cdot 80 \pm 0 \cdot 31^{* *}\end{array}$ & $\begin{array}{l}0.72 \pm 0.27 \\
0.67 \pm 0.28^{* * *}\end{array}$ & . \\
\hline \multirow[t]{2}{*}{ Adherence $\%$} & C & $63 \cdot 9 \pm 17 \cdot 9+$ & $61 \cdot 4 \pm 18 \cdot 4$ & $54 \cdot 6 \pm 20 \cdot 9$ & $59 \cdot 6 \pm 15 \cdot 9+$ & \multirow{2}{*}{$22-95$} \\
\hline & $\mathbf{F}$ & $63 \cdot 9 \pm 23 \cdot 4$ & $65 \cdot 6 \pm 19 \cdot 1$ & $62 \cdot 0 \pm 27 \cdot 0$ & $66 \cdot 5 \pm 18 \cdot 0$ & \\
\hline
\end{tabular}

"p<0.05. * $p<0 \cdot 01 .{ }^{* * *} p<0.001$. The statistical analysis refers to the comparison with the values from day 1 .

tNo significant differences were found between the values from day 1 or 11 and the normal values. 
PMN BACTERICIDAL CAPACITY $\triangle \%$ living CFU after incubation for 45 min

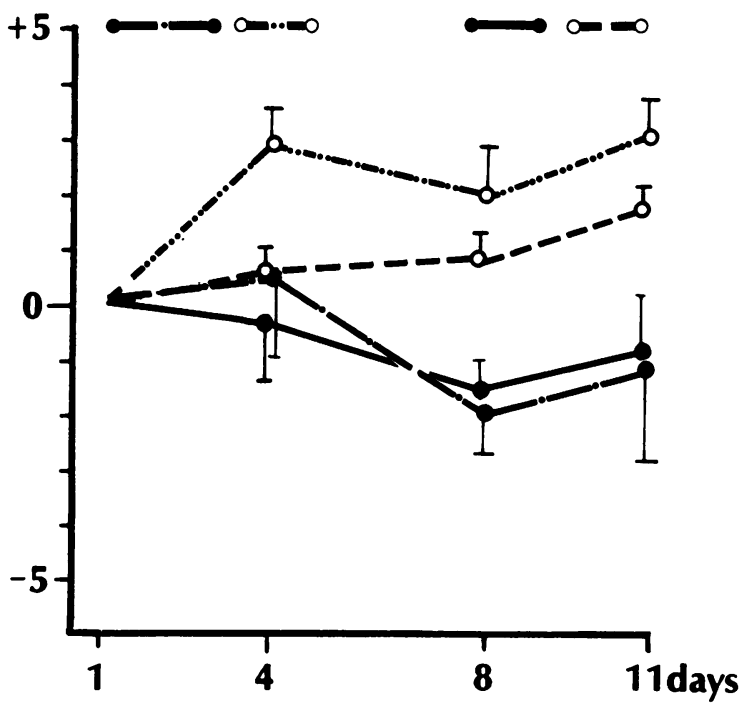

Fig. 3 Deviations in PMN bactericidal capacity after incubation for $45 \mathrm{~min}(\bullet-$ and $\circ \cdots-0)$ and $90 \mathrm{~min}$ $(\bullet-\bullet$ and $\circ---\circ)$ during the fasting period $(\bullet)$ and the control period (०). Mean and $S E$ values. The mean $( \pm S D)$ values for the $R A$ patients on control days 1 and 11 were $3 \cdot 1 \pm 1 \cdot 7 \%$ and $6 \cdot 3 \pm 2 \cdot 8 \%$ CFU of Staph. aureus, respectively, for the $45 \mathrm{~min}$ incubation period, and $1 \cdot 1 \pm 0 \cdot 4 \%$ and $2 \cdot 9 \pm 1 \cdot 7 \% C F U$, respectively, for the 90 min incubation period. The normal values (mean $\pm 2 S D$ ) are: $2 \cdot 7-14 \cdot 8 \% \mathrm{CFU}$ for the $45 \mathrm{~min}$, and $0 \cdot 5-5 \cdot 4 \% \mathrm{CFU}$ for the 90 min incubation periods.

\section{Results}

During fasting the patients lost $5 \cdot 1 \pm 0 \cdot 7 \mathrm{~kg}$ weight (mean $\pm \mathrm{SD}$ ) while no reduction could be registered during the control period $(0 \cdot 3 \pm 0 \cdot 4 \mathrm{~kg})$. A significant $(\mathrm{p}<0.001)$ clinical improvement was observed during fasting as judged by Ritchie's index and morning stiffness (Fig. 4), as well as joint count and Lansbury's index (Table 2), but no changes were found during the corresponding days in the control period.

The ESR fell during fasting (i.e., from day 1 to day 8) from a mean ( $\pm S D$ ) of $51 \cdot 0 \pm 7 \cdot 4 \mathrm{~mm}$ to $41 \cdot 0 \pm 6 \cdot 4$ $\mathrm{mm}(\mathrm{p}<0.05)$. No statistically significant changes occurred during the control period.

No significant changes were noted for serum cortisol during the control of fasting periods (data not shown).

GRANULOCYTE FUNCTIONS

To see whether granulocyte function in patients with

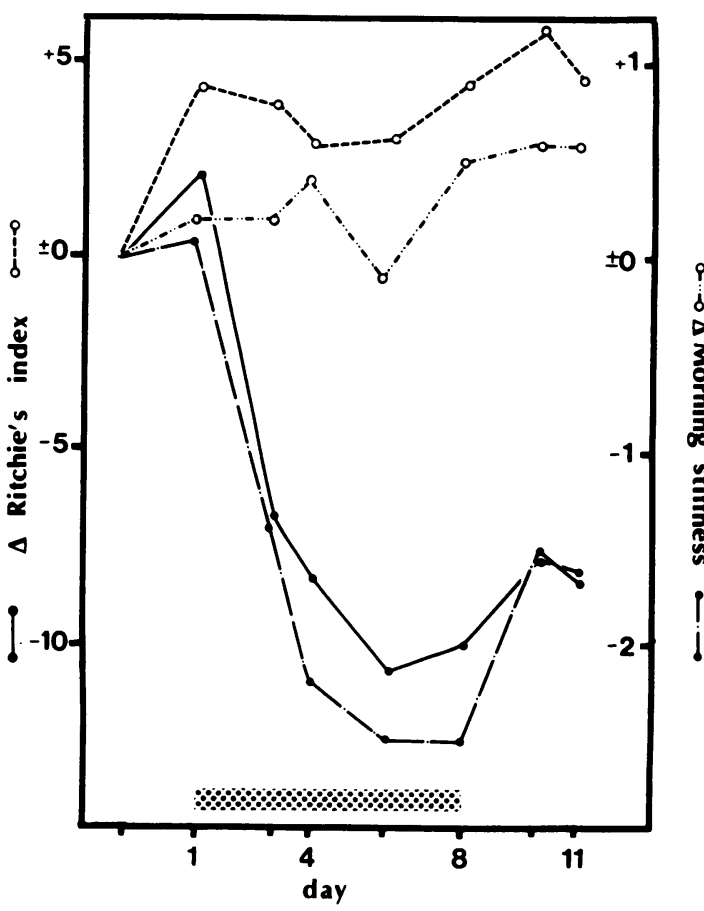

Fig. 4 Deviations $(\Delta)$ in joint tenderness, expressed as Ritchie's index ( $\longrightarrow$ and $\circ-\infty)$, and morning stiffness $(\bullet-\cdots$ and $\circ \longrightarrow \cdots)$, from joint status before the start of the fasting $(\bullet)$ and the control $(\circ)$ periods. The shaded area indicates the duration of the fasting and control periods.

Table 2 Clinical joint inflammatory activity in patients with rheumatoid arthritis during the fasting $(F)$ and control $(C)$ periods. Mean and $S E$ values

\begin{tabular}{llll}
\hline & & Day 1 & Day 8 \\
\hline Joint count $\S$ & F & $20 \cdot 5 \pm 3 \cdot 9$ & $11 \cdot 9 \pm 4 \cdot 5^{* *+}$ \\
& C & $16 \cdot 9 \pm 3 \cdot 0$ & $17 \cdot 7 \pm 3 \cdot 7$ \\
Lansbury's index 8 & F & $80 \cdot 9 \pm 17 \cdot 0$ & $45 \cdot 9 \pm 12 \cdot 0^{* *+}$ \\
& C & $69 \cdot 5 \pm 10 \cdot 3$ & $82 \cdot 5 \pm 16 \cdot 6$ \\
\hline
\end{tabular}

$*$ *p<0.01.

+The statistical analysis refers to a comparison with the values from day 1 . $\S$ For definitions of joint variables see text.

RA was different from that of healthy controls we compared the values for the rheumatoid patients from both day 1 and day 11 of the control period with those for the healthy subjects (Figs. 2, 3; Table 1). No significant differences $(p>0.05)$ were found for locomotion, adherence, or bactericidal capacity on either day. However, for 2 of the patients spontaneous and BF-induced migrations were decreased on day 11 .

\section{EFFECT OF FASTING ON PMNS}

Compared with the value on day 1 the mean value for 
granulocyte migration induced by serum was decreased as early as fasting day $4(p<0 \cdot 01)$, as well as on the last fasting day, that is, day $8(p<0.001)$. On day 11 , that is, during the refeeding period, the migration value was higher than on day 8 but still lower than on day $1(p<0.05)$ (Fig. 2). No changes of locomotion were noted when BF was used as stimulant (Fig. 2). The random migration values were lower on day 4 than on day 1 , but no change occurred thereafter (Table 1). The values for the generation of cytotaxins from the patient's plasma diluted $50 \%$ were lower on day 11 than on day 1 (Table 1), whereas no changes were noted for the undiluted plasma samples (data not shown).

PMN adherence did not change (Table 1).

The PMN bactericidal capacity improved slightly slightly during the latter part of the fasting period. The mean value for the late phase of the bactericidal process was increased on day 8 , that is, the $90-\mathrm{min}$ colony-forming unit (CFU) percentage was lower than the corresponding value for day $1(\mathrm{p}<0 \cdot 05$; Fig. 3 ). No other changes were noted for the bactericidal capacity during the fasting period.

\section{CONTROL AND FASTING PERIODS}

During the control period the PMN migration induced by serum as well as BF was decreased. On day 8 the values for migration induced by both cytotaxins were significantly lower than on the first day ( $p<0.001$ and $p<0.01$, respectively), but on day 11 the values had increased again and were similar to the day 1 values (Fig. 2). The random migration values were higher on day 4 than on day 1 , but no changes were noted thereafter (Table 1).

When the reactions noted during the control period were compared with those from the fasting period it was found that the values for migration induced by BF on day 8 of the control period were significantly lower than those of the same day of the fasting period $(p<0.001$; Fig. 2). No significant changes between the 2 regimens were noted on either day for serum-induced locomotion. Random migration increased significantly on day $4(\mathrm{p}<0.01)$ during fasting in comparison with the control period (Table 1).

The generation of cytotaxins from the plasma samples did not change during the control period. However, the decreased value for the diluted samples on day 11 in the fasting period was significantly lower than on the same control day $(p<0 \cdot 01$; Table 1$)$.

PMN adherence did not change and was not different from that of the fasting period (Table 1).

The bactericidal capacity of the granulocytes decreased during the control period. On day 4 the early phase of the bactericidal process was impaired, that is, the mean $45 \mathrm{~min}$ CFU percentage values were higher than on day $1(\mathrm{p}<0.01)$ whereas the mean 90 min percentage remained unaltered. The $45 \mathrm{~min}$ percentage value was still increased on days 8 and 11 $(p<0.01)$, and on the latter day also the mean 90 min percentage value was higher than on day 1 $(p<0.001)$, indicating that the late phase also of the bacterial killing was impaired at that day (Fig. 3). The changes in the bactericidal capacity noted in the 45 and $90 \mathrm{~min}$ percentage values were significantly different on day 8 of the control period from those on the same day of the fasting period $(p<0.05$ and 0.01 , respectively), but no statistically significant changes were noted between the periods on the other days.

CLINICAL PERFORMANCE AND THE

BACTERICIDAL CAPACITY OF NEUTROPHILS

To assess whether the neutrophil reactions were associated with the clinical response to the fasting, the change of the bactericidal capacity between days 1 and 8 for each patient was related to change of body

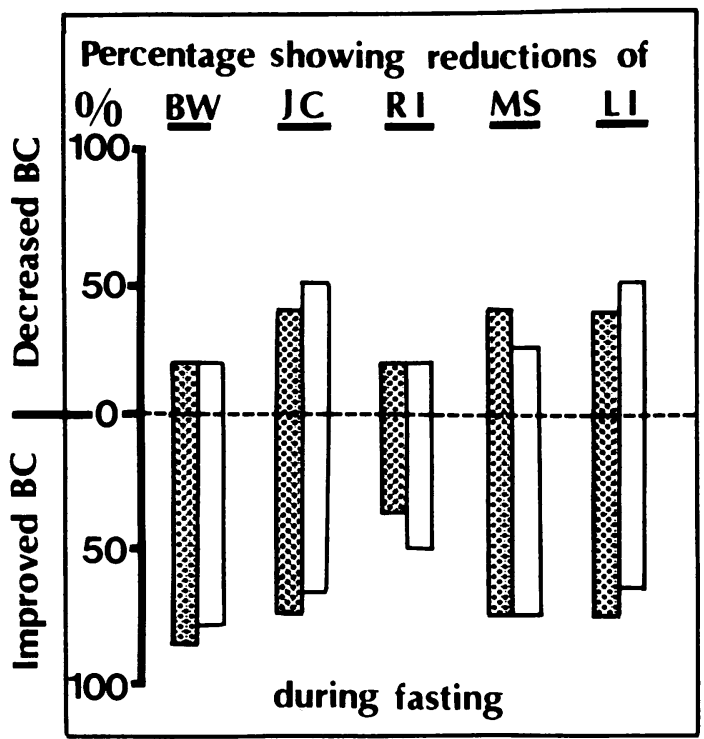

Fig. 5 The relationship between changes of neutrophil bactericidal capacity $(B C)$ and changes of joint measures and body weight during fasting. symbols repreșent the 45 min incubation values and $\square$ the 90 min values for $B C$. The patients who showed a decreased bactericidal capacity during fasting are represented within the upper part of the figure, and those with improved $B C$ in the lower half. The bars depict the percentage of patients within each $B C$ category who had reductions of body weight $(B W)$ during the 2 days preceding the blood sampling, reductions of joint count (J C, more than 5 units), of Ritchie's index (R I, more than 15 units), of morning stiffness (MS, more than 2 units) and of Lansbury's index (L I, more than 15 units). 
weight, joint counts, Ritchie's index, morning stiffness, and Lansbury's index in the same period. The results are depicted in Fig. 5. It shows that a significant proportion of patients with improved bactericidal capacity also had the greatest reductions of body weight and rheumatoid joint activity. Likewise those who reacted with a reduction of the bactericidal capacity during the control period were in general those who experienced a deterioration of the clinical status.

\section{Discussion}

A controlled study on the effects of fasting on patients with rheumatoid arthritis has not to our knowledge been previously published. During fasting the joints of the majority of the patients with rheumatoid arthritis improved, whereas they either remained unchanged or deteriorated during the control period. Hence, since no adverse effects of fasting were noted, it is suggested that short-term fasting may induce a rapid clinical improvement in rheumatoid arthritis. Further investigations are needed to establish its long-term effects.

Since the neutrophil is one of the principal effector cells for inflammation, it is noteworthy that the patients who showed the greatest improvement in joint status during fasting were generally those who showed the greatest improvement in neutrophil bactericidal capacity. The contrary was true for the control period, that is, those who deteriorated clinically showed a decreased neutrophil bactericidal capacity.

Granulocyte functions have previously been investigated in RA. Particle uptake was observed in some studies to be normal ${ }^{112}$ and in others impaired. ${ }^{13}{ }^{14}$ In the present study we found normal bactericidal capacity of Staph. aureus, which is in agreement with previous reports. ${ }^{14}{ }^{15}$ Thus, although particle uptake appeared to be either normal or reduced, killing capacity was normal. The stimulated locomotion of PMNs of the medically untreated patients with rheumatoid arthritis in the present study was within the normal range. This finding is in agreement with those of Walker et al. ${ }^{16}$ but in contrast to those of Mowat and Baum ${ }^{17}$ and RobertsThomson et al. ${ }^{18}$ who, using a micropore filter assay, reported a depressed mean chemotactic index in RA patients. This discrepancy may depend on the different assay systems used or on differences in concomitant administration of anti-inflammatory drugs or on both.

In studies of PMNs from fasting healthy subjects and uninfected subjects suffering from chronic undernutrition PMN bactericidal capacity has usually been depressed, whereas chemotaxis has been normal. $^{131920}$ The present findings differ only on the bactericidal capacity. Although the causes are unknown, it seems reasonable to relate this discrepancy to the relatively short time of fasting investigated here and to the fact that the present patients were afflicted with a disease that clinically reacted positively to fasting.

Migration of PMNs induced by BF and serum was lower during the control period on day 8 than on days 1 and 11. Random migration was enhanced during the same period, though less markedly. Other investigations suggest that circulating immune complexes and/or the generation of migration inhibitory factors secondary to discontinuation of previous medication might be involved. ${ }^{21}$ These could influence neutrophils during such a limited time period. ${ }^{22}$ For instance, immune complexes might deactivate surface receptors on circulating PMNs. Indeed, deactivation of PMNs in vivo might be expected to be associated with a decreased stimulated migration to a related cytotaxin (serum in the present study) and, if the complexes are present in high concentrations, even to unrelated cytotaxins-for example, to both serum and BF-together with increased random migration and decreased bactericidal capacity ${ }^{23}$ (as found here) and, possibly, enhanced release of lysosomalo enzymes. ${ }^{24} \mathrm{~A}$ sequence of events as suggested here could explain the clinical deterioration as well as theo changes in migratory response during the control? regimen. Moreover, this deactivation hypothesis might explain why migration induced by serum was decreased, although BF-induced migration was unaffected during the fasting period. Together with the enhanced bactericidal capacity and decreased spontaneous migration these changes might indicate that the influence of, for example, immune complexes secondary to disease and previous treatment was reduced by fasting. These findings also stress the importance of using not a single but several different chemotactic factors when studying PMN migration. ${ }^{85}$ To conclude we suggest that fasting reduced the impact of migration inhibitory factors, allowing $\mathrm{BF}$ to elicit a normal and unchanged response.

Thus the fasting of patients with rheumatoid arthritis could be considered to induce anti-inflammatory influences, as suggested by the decrease in joint tenderness and swelling produced by fasting in our patients. Finally, since serum cortisol levels were unchanged, it seems less probable that any of the joint and neutrophil effects were mediated by an increased pituitary-adrenal activity secondary to the stress of acute starvation.

\footnotetext{
References

${ }^{1}$ Palmblad J. Fasting (acute energy deprivation) in man: effect on polymorphonuclear granulocyte functions, plasma iron and serum transferrin. Scand J Haematol 1976; 17: 217-26.
} 
${ }^{2}$ Holm G, Palmblad J. Acute energy deprivation in man: effect on cell-mediated immunological reactions. Clin Exp Immunol 1976; 25: 207-11.

${ }^{3}$ Palmblad J, Cantell K, Holm G, Norberg R, Strander H, Sundblad L. Acute energy deprivation in man: effect on serum immunoglobulins, antibody response, complement factors 3 and 4, acute phase reactants and interferon-producing capacity of blood lymphocytes. Clin Exp Immunol 1977; 30: 50-5.

4 Palmblad J, Levi L, Burger A, et al. Effects of total energy withdrawal (fasting) on the levels of growth hormone, thyrotropin, cortisol, adrenaline, noradrenaline, $\mathrm{T}_{4}, \mathrm{~T}_{3}$ and $\mathrm{rT}_{3}$ in healthy males. Acta Med Scand 1977; 201: 15-22.

5 Ropes M W, Bennet G A, Cobb S. 1958 revision of diagnostic criteria for rheumatoid arthritis. Bull Rheum Dis 1958; 9: 175-86.

- Ritchie D M, Boyle M A, McInnes J M, et al. Clinical studies with an articular index for the assessment of joint tenderness in patients with rheumatoid arthritis. $Q J$ Med 1968; 37: 393-406.

7 Lansbury J. Report of a three-year study on the systemic and articular indexes in rheumatoid arthritis. Arthritis Rheum 1958; 1: $505-22$.

B Afzelius B, Palmblad J, Udén A-M; Venizelos N. Neutrophil function in patients with immotile cilia-syndrome. Acta Med Scand 1980; 208: 145-54.

- MacGregor R R, Spagnuolo P J, Lentnek A L. Inhibition of granulocyte adherence by ethanol, prednisone and aspirin, measured with an assay system. $N$ Engl J Med 1974; 291: 642-6.

10 Palmblad J, Engstedt L. Activation of the bactericidal capacity of blood granulocytes - evaluation of a new method and the effect of levamisole. Acta Pathol Microbiol Scand (C) 1979; 87: $357-66$.

11 Brandt L, Hedberg $H$. Impaired phagocytosis by peripheral blood granulocytes in systemic lupus erythematosus. Scand $J$ Haematol 1969; 6: 348-53.

12 Hällgren $R$, Håkansson $L$, Venge $P$. Kinetic studies of phagocytosis. I. The serum independent particle uptake by PMN from patients with rheumatoid arthritis and systemic lupus erythematosus. Arthritis Rheum 1978; 21: 107-13.

${ }^{13}$ Corberand J, Amigues H, de Larrard B, Pradere J. Neutrophil functions in rheumatoid arthritis. Scand J Rheumatol 1977; 6: 49-52.
14 Wilton J M A, Gibson T, Chuck C M. Defective phagocytosis by synovial fluid and blood polymorphonuclear leucocytes in patients with rheumatoid arthritis I. The Nature of the defect. Rheumatol Rehabil 1978; suppl: 25-35.

15 El-Ghobarey A F, Mavrikakis M E, Macleod M, et al. Clinical and laboratory studies of levamisole in patients with rheumatoid arthritis. $Q J$ Med 1978; 47: 385-400.

16 Walker J R, Smith M J H, James D W. A comparison of two in vitro methods for studying a defect in leucocyte movement in rheumatoid arthritis. Int Arch Allergy Appl Immunol 1979; 59: 343-8.

${ }_{17}$ Mowat A G, Baum J. Chemotaxis of polymorphonuclear leukocytes from patients with rheumatoid arthritis. J Clin Invest 1971; 50: 2541-9.

18 Roberts-Thomson P J, Hazleman B L, Barnett I G, MacLennan I C M, Mowat A C. Factors relating to circulating immune complexes in rheumatoid arthritis. Ann Rheum Dis 1976; 35: 314-20.

19 Palmblad J, Fohlin L, Lundström H. Anorexia nervosa and polymorphonuclear (PMN) granulocyte reactions. Scand J Haematol 1977; 19: 334-42.

${ }^{20}$ Douglas S D, Schopfer K. The phagocyte in protein-calorie malnutrition. In: Suskind $\mathrm{R} \mathrm{M}$, ed. Malnutrition and the Immune Response. New York: Raven Press, 1977.

${ }^{21}$ Kemp A S, Roberts-Thomson P, Neoh S H, Brown S. Inhibition of neutrophil migration by sera from patients with rheumatoid arthritis. Clin Exp Immunol 1979; 36: 423-9.

22 Camussi G, Emanuelli G, Ragni R. Interaction between immunocomplexes (ICs) and polymorphonuclear neutrophils (PMNs). Panminerva Med 1978; 20: 103-5.

23 Spilberg I, Mandell B, Hoffstein S. A proposed model for chemotactic deactivation. J Lab Clin Med 1979; 94: 361-9.

24 Showell H J, Williams D, Becker E L, Naccache P H, Sha'afi R. Desensitization and deactivation of the secretory responsiveness of rabbit neutrophils induced by the chemotactic peptide, formyl-methionyl-leucyl-phenylalanine. $J$ Reticuloendothelial Soc 1979; 25: 139-49.

${ }^{25}$ Issekutz A, Lee K Y, Biggar W D. Neutrophil chemotaxis in two patients with recurrent staphylococcal skin infections and hyper-immunoglobulin E.J Lab Clin Med 1978; 92: 640-7. 